\title{
EPIDEMIC ASTHMA SURVEILLANCE IN THE NEW ENGLAND REGION 1990-1992
}

Justine Waters, New England Region Public Health Unit, Stephen Corbett, Epidemiology and Health Services Evaluation Branch

Peter Gibson, Michael Hensley and John Wlodarczyk, Newcastle Environmental Toxicology Research Unit

\section{INTRODUCTION}

$\Delta \mathrm{n}$ epidemic of acute asthma occurred in Tamworth and surrounding towns in the New England Region of north-eastern NSW on November 1, 1990. The epidemic was preceded by a brief thunderstorm and, over a five-day period, 110 people attended the Accident and Emergency departments (A\&E) of Tamworth and Quirindi hospitals. Thirty-eight of these people required hospital admission. During the same period at least 123 people attended local general practitioners (GPs) with symptoms of acute asthma ${ }^{1}$. Late spring epidemics of similar magnitude, but of less severity, occurred in three of the previous five years for which data were available.

A review of clinical information obtained from epidemic asthma cases, and meteorological and agronomic data, pointed to exposure to rye grass pollen as the probable cause of this and previous epidemics. The hypothesis was that tonnes of pollen were drawn up into the body of the advancing storm. They then fragmented into starch particles of respirable size which were subsequently deposited on the affected towns during the thunderstorm.

To test this hypothesis, asthma occurrence and pollen levels were again monitored in the Tamworth region during spring in 1991 and 1992. In this article, we report results of this surveillance and an assessment of the likely public health impact of this seasonal phenomenon, based on a two-year follow-up of people affected by the 1990 epidemic.

\section{METHODS}

\section{Asthma surveillance}

Surveillance systems for acute asthma epidemics in the Tamworth region were developed in 1991 and well established by spring 1992. Surveillance during 1992 included:

\section{- A\&E surveillance}

The Triage register at the Tamworth Base Hospital was examined daily for attendances for asthma from September 1 to December 1, 1992. Case notes were reviewed for all 'suspected' asthma entries.

\section{GP surveillance}

The New England Region Public Health Unit (NER PHU) has established sentinel GP surveillance throughout the Tamworth region. Sixteen GPs regularly participate in this surveillance and acute asthma is one of the five notifiable conditions. Of these GPs, 14 provided weekly data on the number of acute asthma attendances at their practices for the three-month surveillance period in 1992. An additional 17 GPs agreed to participate in the surveillance for the duration of the study period only and of these, 10 provided data.

\section{Symptom diaries for asthmatics}

In 1992, 58 asthmatics identified from the 1990 epidemic were contacted by letter and asked to participate in the symptom diary study. Using previously piloted symptom diaries, they were asked to record the severity of their asthma symptoms from mid-October to mid-November. Symptoms of cough, wheeze, itchy and runny nose/eyes were graded on a scale of 1 (no symptoms) to 7 (worst symptoms ever) and were recorded each morning and night. These symptoms were then grouped into asthma and hayfever scores for each day. The asthmatics were again contacted by letter and telephone to return their completed diaries.

\section{Pollen monitoring}

Two pollen monitoring sites were selected in Tamworth and a third in Gunnedah for the location of the Burkard sevenday recording spore traps. Pollen grains were collected daily by impaction on the adhesive surface of traps and at the end of seven days the tapes were sent for counting and pollen typing. Pollens were grouped into grasses, plantain, cypresses/pine, Patterson's curse and miscellaneous.

\section{Meteorology}

Data were obtained from both the Australian Bureau of Meteorology (Melbourne) and a meteorology station monitored by Pacific Power a few kilometres south of Tamworth.

\section{RESULTS \\ Asthma surveillance}

One hundred and twenty-five people attended the A\&E department of Tamworth Base Hospital for acute asthma during the three-month period - an average of 1.37 cases a day. On no day did the number of attendances exceed the 15-day moving average attendance rate for asthma. (An epidemic day was defined as such if the number of asthma attendances exceeded the 15-day moving average with a poisson probability $<0.0001$ ). In contrast, the data for 1990 in Figure 1 show an obvious epidemic.

GP surveillance revealed 348 consultations (from 24 GPs) for acute asthma during the three-month period and graphing this data revealed no obvious asthma epidemic days. In contrast, 14 GPs recorded 123 attendances for acute asthma over the four-day epidemic period in 1990.

At the end of the 1992 study period, 30 of the 58 ( 52 per cent) symptom diaries sent out to the identified asthmatics were returned for analysis.

In 1990, 20 per cent of epidemic asthma cases had no prior history of asthma symptoms. When these people were followed up during the pollen season 12 months later, 60 per cent reported recurrent asthma symptoms, 47 per cent were using inhaled bronchodilators for symptom relief and 53 per cent had seen a medical practitioner for asthma management. These 'new-onset' asthmatics have similar levels of histamine airway responsiveness and airway eosinophilia to epidemic cases with pre-existing asthma but did not have mast cells in airway secretions.

\section{Pollen monitoring}

The data in Figure 2 are based on the average of total grass pollen counts of the two Tamworth pollen monitoring stations. Grass pollen levels increased dramatically in midOctober 1992 and remained high until the end of the study period.

Diary data indicates that both hayfever and asthma symptoms also tended to increase around this time. Despite several days of storm activity around November 1 , there was no evidence of an asthma epidemic in this period. 


\section{FIGURE 1}

DAILY ACUTE ASTHMA ATTENDANCES AT TAMWORTH BASE HOSPITAL IN RELATION TO TEMPERATURE AND RAINFALL, SPRING 1990 AND 1992
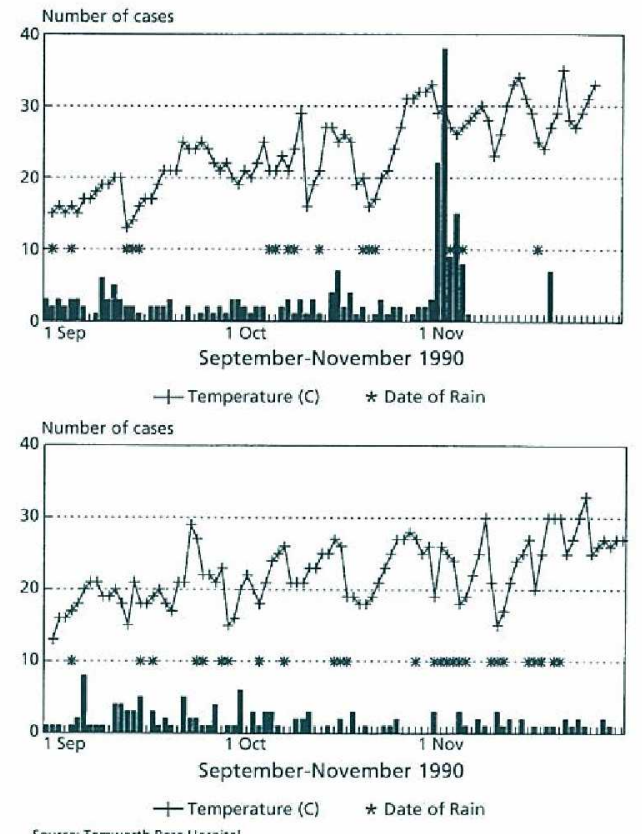

\section{FIGURE 2}

RESULTS OF THE TAMWORTH POLLEN MONITORING AND SYMPTOM DIARIES FOR SPRING 1992

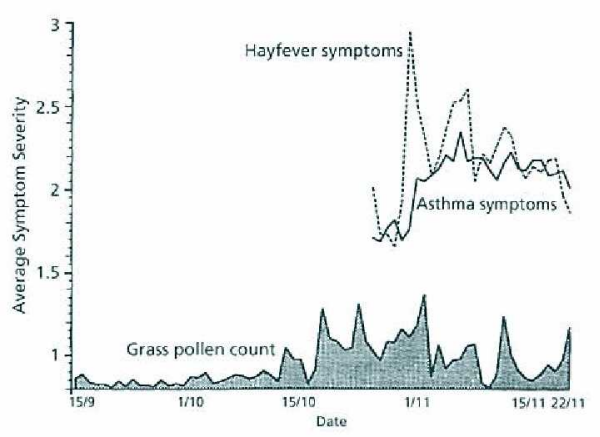

Asthma score $=$ Mean (cough on previous night+wheeze on previous night+tightness on previous night+shortness of breath on previous night+cough during day+wheeze during day+tightness during day+shortness of breath during day)

Hayfever score $=$ Mean (eyes+nose symptoms)

\section{Meteorology}

Weather conditions in the spring of 1990 and 1992 were similar (Figure 1). As in 1990, there were several days of storm activity around November 1, 1992, although the temperatures in 1990 were higher on average. However, there were no winter rains in 1992 and these drought conditions yielded poor growth of pasture crops such as rye and barley grasses.

\section{CONCLUSION}

'Thunderstorm asthma' has been shown to be a recurrent late spring phenomenon in the Tamworth region. These epidemics of asthma occur in people with pre-existing hayfever and allergy to grass pollens.

The dramatic epidemic of 1990 has not recurred in subsequent years. In 1991 and 1992, low winter rainfalls inhibited the growth of rye and barley grasses. The pollens of these grasses, transported and fragmented in an advancing thunderstorm, were the likely cause of the 1990 epidemic.

Asthma and aeroallergen surveillance over this period has demonstrated that asthma and hayfever symptoms become more common when levels of rye and barley grass pollen begin to increase in mid-October. Symptoms of hayfever preceded asthma symptoms and an increase in hayfever symptoms may indicate a potential worsening of asthma symptoms. Follow-up of people who developed asthma symptoms for the first time during the 1990 epidemic suggests this event had some lasting effects on symptom occurrence.

The investigation of the 1990 epidemic, and subsequent surveillance of asthma, provided an opportunity to inform and educate the community about asthma recognition and to reinforce aspects of both short-term and long-term asthma management. The local media were given a role in informing the public about asthma management and prevention, and warning the community about possible asthma epidemics. An Asthma Awareness and Information Day was held in Tamworth on March 31, 1993, with the aim of providing feedback and information to the community and health service providers. The results of the 1990-1992 investigations and surveillance were presented and the need for asthma action plans and management in the event of future epidemics was emphasised.

Community-wide surveillance of asthma symptoms and pollen counts in the Tamworth region has proved to be:

- effective and cost-efficient, and accepted and supported by both health service providers and the community as a whole; and

$\square$ useful in providing valuable information and early warning signs for appropriate public health action.

Accordingly, it has been decided to continue these surveillance activities in the region during the months of spring. Intervention trials may be initiated in 1993 if an epidemic seems likely based on prevailing agricultural conditions. There is good evidence that epidemics of asthma are not confined to the Tamworth region ${ }^{2.3}$. The surveillance methods used in this study could be used to document the occurrence of asthma epidemics in other areas of NSW.

\section{ACKNOWLEDGMENTS}

We gratefully acknowledge the contributions by Ruth Toneguzzi (Newcastle Environmental Toxicology Research Unit), the staff of the New England Public Health Unit and Tamworth Base Hospital, and Pacific Power (Head Office, Sydney).

1. Corbett SJ, Hensley MJ, Gibson P, Wlodarczyk J, Bek M, Katelaris $\mathrm{CH}$. Recurrent Epidemic Asthma in a Rural Australian Community in press

2. Suphioglu C, Singh MH, Taylor P, Knox RB. Mechanism of grasspollen-induced asthma. Lancet 1992 339:569-72.

3. Smart IJ, Tuddenham WG, Knox RB. Aerobiology of Grass Pollen in the City Atmosphere of Melbourne: Effects of Weather Parameters and Pollen Sources. Aust J Bot 1979 27:333-42. 